\title{
Determinants of Effective Financial Risk Management in Small Business: A Theoretical Framework
}

\author{
Nurulhasanah Abdul Rahman*, Zulnaidi Yaacob, Rafisah Mat Radzi \\ Universiti Sains Malaysia, Penang, Malaysia \\ *hasanah.rahman89@yahoo.com
}

\begin{abstract}
This paper aims to develop a theoretical model of potential determinants of effective financial risk management in small business. In achieving this objective, the methodology used includes library search and analyzing previous literature review on the subject of financial risk management and small business especially in Malaysia case study. The significant variables are namely the leadership, training programs, use of technology, entrepreneurship orientation (EO) and accounting information. This paper also hopes to strengthen the body of knowledge on how financial risk management helps small business towards success, besides to act as a reference for empirical research.
\end{abstract}

Keywords: Financial risk management, small business, Malaysia

\section{Introduction}

What is financial risk management? Why is it important for small business? These are the questions that come across any small business owners whenever financial risk is being discussed. A successful development and survival of small and micro firms depend on the role of financial management which has been continually recognized by the Bank of England in its annual report (Deakins, Logan \& Steel, 2001). Back then, it is mere definition and introduction to the theory but still, the gist of having financial risk awareness is low. The gap which regularly reported by numerous scholars are about the gap involving accounting theory and its practice (Scapens, 1985 as in Berry, Sweeting, Goto \& Taylor, 2002) is due to the fact that managers decline the sophisticated accounting techniques even though the theoretical advantages are significant to business; but still practicing a more mundane approaches (see Berry et al., 2002). The prominence of implementing proper financial risk management is not well adapted especially in Malaysia. For that reason, this paper will go in depth on how exactly financial risk management can be fully utilize for small business using proposed framework. So, how to close the gap? Simply stated as educating small business owners on this matter and highlight the significance of having effective financial risk management in business may help to resolve this issue. Hence, financial risk will be no longer alienated from small business. A good financial risk management apparently will safeguard the survival rate of small business within the early stage of establishment (Bolden, 2007). Therefore, there is an urgency to study the effective financial risk management in small business so that the business owners may achieve better business performance in future.

\section{Significant of study}

- To date, there is a limited pool of resources regarding small business and financial risk management in Malaysia which hinder business owners from a prosperous income. Therefore, findings from this paper may act as a reference for empirical research and contribute to the literature review especially for Malaysian case study.

- Malaysian government had introduced a lot of programs as well as national policies but small business in Malaysia is not at their best level. The survival rate is still low which demands a comprehensive framework to assist the small owners pertaining financial matters. Also, the highlight on financial risk management is crucial as it is the core of strategic planning for business. 


\section{Research Objective}

To develop an extended theoretical framework on the determinants of effective financial risk management for small business.

\section{Literature Review}

This section explains the definition of small business in Malaysia. Later, the definition of financial risk management and its importance are being discussed comprehensively. Then, each variable are deliberate accordingly before constructing an extended theoretical framework. To date, there is a limited literature review on financial risk management which makes it quite challenging to provide a solid definition for small business. Indeed, there is no exact consensus among researchers on how to define the exact definition of financial risk management among small business. Yet, its importance towards the survival of small business is undeniable. Therefore, there is an urgency to place financial risk management as the focus of this paper to improve the small business's survival and business performance. Typically, Asian countries are more open and fast forward in adopting small business as their source of income. For instance, in Malaysia alone, there are 99 percent of the total business units are SME. In this connection, there are three main sectors of small business in Malaysia which comprise sectors of Services, Agriculture and Manufacturing. SMEs in Malaysia as reported in SMEinfo (2011), a website for SME current news and updates, currently contribute 31 percent national GDP and allocate 56 percent of the total job opportunity in Malaysia. Deriving the definition of small business or SME from SME Corporation Malaysia (2013) emphasize that the definition is varies according to type of business and also depends on the sectors. For example, SME or small business across any sectors, the sales turnover should be less than RM300,000 to RM15 million or permanent employees are not exceeding five to 75 permanent employees (revised 1 January 2014). Regardless of this fact, small business still needs improvement especially in terms management and financial issues.

Rauch and Frese (2000) explained that small-scale business is known as they are providing variety of job opportunities to the community compared to the large business. It requires less formal education level entry and more flexible recruitment process. However, it is also an easy way for the small business to eliminate them due to of a higher failure rate. By comparing small business and large firms, the small business is actually easier to be initiated, supple, give immediate respond and act promptly to the volatile market condition. It is also known that SME are more innovative and offer personalized attention which contributes to a closer reach to customers. In contrast, the small-scale firms also often have weak financial resources, lower wages, little productivity and strategic marketing elements as well as low awareness to expand business for internationalization process (Mulhern, 1995). Doing business, particularly a small business is always been misinterpret as the ultimate source of income to the poor household. This statement is not totally wrong but its establishment alone is not sufficed. Among the most discussed risks involved in SME are establishment of business entity, low collection in account receivables, incapacity to go for technological advancement and high employee turnover (Panigrahi, 2011). Similar with a study conducted by Aziz, Awang and Zaiton (2012), they proposed that financial limitation, high taxes imposed to business, lack of government support and successor programs categorized as the common challenges faced by SME. Other than that, the structural weaknesses found in SME are mostly circulated in terms of technology adoption, research and development activities, lack of technical, professional and management proficiency which had hinder the SME potential to grow (Radam, Abu \& Abdullah, 2008).

According to Dionne \& Triki (2003), researchers are trying to find exact definition of risk management but there is no well-accepted framework that practitioners can rely on when formulating risk management strategies. Every definition is different according to countries, business setting and environment. Nevertheless, Fatoki (2012) had summarized the definition of financial management from Gitman (2007), Oduware (2011), Brinkmann, Salomo \& Gemueden (2011) and Management Study Guide (2012). Gitman (2007) had come out with financial management definition as the area of business management field, devoted to a careful use of capital and its sources of selection, in order to assist the organization to achieve its goal. On 
the other hand, Oduware (2011) further stated that financial management is the planning for future to ensure a positive cash flow of a business firm. In addition to that, Brinckmann et al. (2011) and Management Study Guide (2012) both agreed in defining financial management as managerial activities which focus on financial capital acquisition and the assurance of its effective and efficient use for business. When it comes to effective financial risk management, different authors have different measurement of this subject matter. Typically, financial risk management emphasize on the liquidity, credit, foreign exchange, interest rate and commodity price risk (CPA Australia, 2009). Further, in quantitative measure of risk management, the focus usually lies on how to improve the measurement and supervision of specific risks such as liquidity, market and credit risk (Aebi, Sabato \& Schmid, 2012). However, this study narrowed down the scope of effective financial risk management to only three main risks discussed in literatures which cover liquidity, credit and business operation risk. The liquidity risk signifies the ability of the business to pay loans whereas the credit risk refers to the business transactions via credit and installments. Business operation risk is refers to the risk engaged in any business operation.

\section{Figure 1: Theoretical Framework}

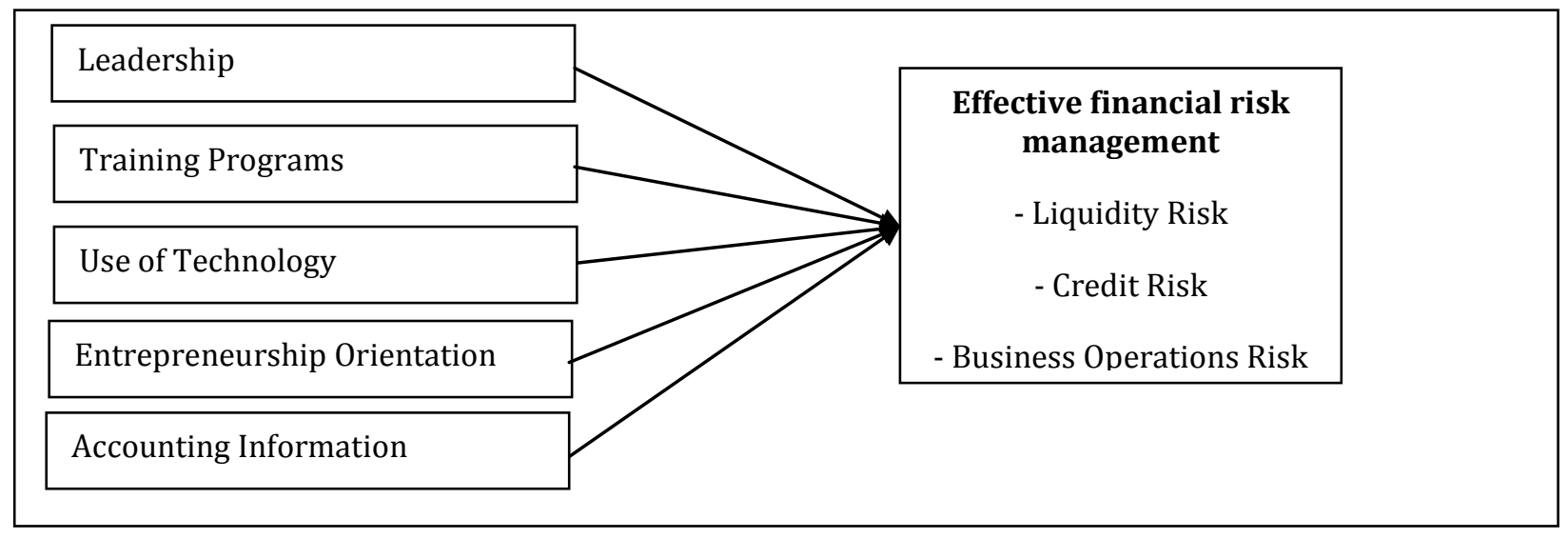

Source: Berg, 2010; Deakins, Logan \& Steel, 2013; Dionne \& Triki, 2003; Duong, 2005; Fatimah-Salwa, Azahari \& Tamkin, 2013; McClelland, Rhinesmith \& Kristenses, 1975; Rauch \& Frese, 2000; Virdi, 2005.

Leadership is referring to the small business owners they are the one who runs the business. The appointment of the Risk Officer or Internal Auditor is rarely happens for small business due to the financial constraints so the responsibilities lies under the owners' themselves. By having particular documentation and separate practices for risk management leads to effective financial risk management. The smaller size of a business means a smaller chain of command and smaller component for the leader to control. Thus, the leader, which in this case, the SME owners to have stronger impact on the company policy, culture and strategy compared to the large business (Rauch \& Frese 2000). McClelland, Rhinesmith \& Kristenses (1975) early study highlight the need for achievement had become the starting point for many researchers around the world to study the characteristics of an entrepreneur. His findings stated that a high need for achievement leads a particular person to prefer challenging assignments of moderate complexity rather than routine or very difficult assignments, they expect employees to be responsible for their performance, to seek out feedback on performance, and to find original and better means to improve their performance.

Many studies described the crucial role of training programs that links to the success of entrepreneurs and business (Cheston and Kuhn, 2002; Jill et al., 2007; Kuzilwa, 2005 as cited in Fatimah-Salwa, Azahari \& Tamkin, 2013). By having a good training program, the entrepreneurs are expected to be well equipped in term of knowledge and skills necessary for them in effectively managing business and which subsequently result to their business success. It starts from establishing goals which refers to the threat of risk and its 
environment, identify, analyze the identified risks, assess or evaluate the risks, manage the risks, monitor the risk and its environment regularly and lastly to continuously communicate the risk strategies (Virdi, 2005; Dionne \& Triki, 2003; Duong, 2005; Berg, 2010). It is viewed as a medium for small business owners to learn and apply knowledge on how to act on risks besides find solution to grow potential of risk to become an opportunity to grow. Moreover, training programs are where new set of skills and information delivered from government or non-government bodies to help small business to survive and commercialized their business (Andersen, Bollerslev, Christoffersen \& Diebold, 2013; Antonites \& Wordsworth, 2009 \& Dinu, 2013).

Use of technology denotes between IT literate and IT illiterate. IT literate refers to the extent to which technology benefits small business whereas IT illiterate refers to the small businesses that do not use the best of technology. According to Association of Malaysia, only 30 per cent of Malaysian SME have a web site for their business and use IT only on a daily basis for regular usage (Hussin \& Noor 2005 as cited in Alam, Jani \& Omar, 2011). By looking at the globalization and information-on-the-fingertip era, SME in the developed countries started adopting e-commerce in their businesses regardless for marketing, communication or formal business purposes (Rao and Metts, 2003) but Malaysian SMEs and also some other developing countries are reluctant to use IT or e-commerce for their business operation. Also, there is evidence that many small businesses are not keeping records especially in terms of computerized record but some others do keep limited business data but it is not comprehensive as they only want to meet the minimal reporting requirements set up by government (Deakins, Logan \& Steel, 2001).

Entrepreneurial orientation (EO) has been suggested as an attribute of successful business. Previous literatures point out that entrepreneurial business should be conceptualized to encompass three main characteristics which are innovativeness, risk-taking, and proactiveness to assess a business's entrepreneurial orientation. It is important for SMEs to be entrepreneurial in order to improve their market share and business performance. Higher EO presents more innovative and risk takers of SME owners/managers compared to lower EO in business (Fairoz, Hirobumi \& Tanaka, 2010). Further, in Chong (2012) study, she affirmed that current empirical facts recommend that effective financial management may contribute to the success of business in the near future. Besides, Shahwan \& Al-Ain (2008) study proposed that the success of business in managing its financial sources should be evaluated by the owner himself/herself in terms of their worth in decision making. Therefore, entrepreneurship orientation with the culture of innovativeness, risk-taking and proactiveness may culminate in business success.

At the same time, Shahwan \& Al-Ain (2008) also argued that users of financial report should be able to make sound decision regarding resource allocation and expected to be capable in managing the resources. Business decision is assumed to be depending on the relevant information produced by the business operators. Such information should be high quality and transparent. In addition, the information can also be viewed in different dimensions, from observe performance, explore relationship and to manipulate trends. Further, Damant (2003) argued that if accounting business information is more insightful on the economic certainty and more transparent, the advantages are not only for the companies but for the community as a whole. Taken from Xu, Nord, Nord \& Lin (2003) study, they concluded that information quality is the information that is vigorous to be used and has four attributes which are accuracy, timeliness, completeness and consistency. In short, comprehensive accounting information will lead a small business to a better state as it will highlight the possible threat in terms of financial risk that business encounter from time to time.

Suggestion for future research: Based on the findings from this paper, it is necessary to test the framework empirically to assess its reliability. The theory alone is not sufficed in explaining the importance of financial risk management for small business. Further, it is encouraged to conduct more research because the literature review regarding financial risk management is still scarce and limited in Malaysian context. The theoretical framework is also required to be tested in different setting such as different countries and to large business. Besides, it is an urgency to construct a new definition of financial risk management because present 
definition is broad and often mislead to another concept. Its overlapping definition warrants future research to be done for a clearer definition.

\section{Conclusion}

The objective of this paper is achieved as an extended theoretical framework on determinants of effective financial risk management is proposed. By reviewing the previous literature, it showed that there is a limited pool of resources on this issue and demands more research to be done regarding this issue. Besides, financial risk management is still new for Malaysian studies especially for small business. Its importance as well as the difference it could create may open up business owners to adopt effective financial risk management for their business. It will surely bring small business to a new level of prosperous performance and profitability results.

Acknowledgement: The authors gratefully acknowledge financial support from Universiti Sains Malaysia (USM), for this paper (1001/PJJAUH/816235).

\section{References}

Aebi, V., Sabato, G. \& Schmid, M. (2012). Risk management, corporate governance, and bank performance in the financial crisis. Journal of Banking \& Finance, 36(12), 3213-3226.

Alam, S. S., Jani, M. F. M. \& Omar, N. A. (2011). An Empirical Study of Success Factors of Women Entrepreneurs in Southern Region in Malaysia. International Journal of Economics and Finance, 2(1)

Andersen, T. G., Bollerslev, T., Christoffersen, P. F. \& Diebold, F. X. (2013). Financial Risk Measurement for Financial Risk Management. Handbook of the Economics of Finance, 1128-1218.

Antonites, A. J. \& Wordsworth, R. (2009). Risk tolerance: A perspective on entrepreneurship education. Southern African Business Review, 13(3), 69-85.

Aziz, Y. A., Awang, K. W. \& Zaiton, S. (2012). Challenges Faced by Micro, Small, and Medium Lodgings in Kelantan, Malaysia. International Journal of Economics and Management, 6(1), 167-190.

Berg, H. (2010). Risk management. Procedures, methods and experiences, 2(17), 79-95.

Berry, T., Sweeting, B., Goto, J. \& Taylor, M. (2002). Financial Management practice amongst SMEs. Working paper series, Manchester Metropolitan University.

Bolden, R. (2007). Leadership Development in SMEs: Designing a customized solution. University of Exeter: Centre for Leadership Studies.

Chong, W. Y. (2012). Critical Success Factors for Small and Medium Enterprises: Perceptions of Entrepreneurs in Urban Malaysia. Journal of Business and Policy Research, 7(4), 204-215.

CPA Australia. (2009). Risk Management Guide for small to medium businesses. CPA Australia Business and Management Centre of Excellence.

Damant, D. (2003). Accounting standards: a new era. Balance Sheets, 11(1), 9-20

Deakins, D., Logan, D. \& Steel, L. (2001). The Financial Management of Small Enterprise. Accountants Chartered Certified Association Research Report, (4), 5-55.

Dinu, A. M. (2013). Risk in financial transactions and financial risk management. Procedia - Social and Behavioral Sciences, 116 (1), 2458 - 2461.

Dionne, G. \& Triki, T. (2003). On risk management determinants: what does really work? Department of Finance and risk management chair, HEC Montreal.

Duong, L. (2005). Effective risk management strategies for small-medium enterprises and micro companies a case study for Viope Solutions Ltd. Degree Thesis: International Business.

Fairoz, M. F., Hirobumi, T. H. \& Tanaka, Y. (2010). Entrepreneurial Orientation and Business Performance of Small and Medium Scale Enterprises of Hambantota District Sri Lanka. Journal of Asian Social Science, 6(3), 34-46. 
Fatimah-Salwa, A. H., Mohd Azahari, A. \& Joni-Tamkin, B. (2013). Success Factors of Successful Microcredit Entrepreneurs: Empirical Evidence from Malaysia. International Journal of Business and Social Science, 4(5), 153-159.

Fatoki, 0. (2012). An Investigation into the Financial Management Practices of New Micro-enterprises in South Africa. Journal of Social Science, 33(2), 179-188.

Gitman, L. J. (2007). Principles of Managerial Finance. New York: Addison Wesley.

McClelland, D. C., Rhinesmith, S. \& Kristensen, R. (1975). The effects of power training on community action agencies. Journal of Applied Behavioral Sciences, 11, 92-115.

Management Study Guide. (2011). Financial Management Meaning, Objectives and Functions. Retrieved February 10, 2012 from http://www.managementstudyguide.com/financialmanagement.htm

Mulhern, A. (1995). The SME Sector in Europe: A Broad Perspective. Journal of Small Business Management, 33, 83-87.

Oduware, U. (2011). Overview of Financial Management. Retrieved January 18, 2012 from http://www.isearch.im/pdf/1/chapter-1-overview- of-financial-management.html

Panigrahi, A. K. (2011). Risk Management in Micro, Small and Medium Enterprises (MSMEs) in India: A Critical Appraisal. Asia Pacific Journal of Marketing \& Management Review, 1(4), 59-72.

Radam, A., Abu, M. L. \& Abdullah, A. M. (2008). Technical Efficiency of Small and Medium Enterprise in Malaysia: A Stochastic Frontier Production Model. International Journal of Economics and Management, 2(2), 395-408.

Rao, S. S. \& Metts, G. (2003). Electronic commerce development in small and medium sized enterprises: a stage model and its implications. Business Process Management Journal, 9(1), 11-32.

Rauch, A. \& Frese, M. (2000). Psychological approaches to entrepreneurial success. A general model and an overview of findings. International Review of Industrial and Organizational Psychology, 3, 101-142.

Shahwan, Y. \& Al-Ain (2008). Qualitative characteristics of financial reporting: a historical perspective. Journal of Applied Accounting Research, 9(3), 192-202.

SMEInfo. (2011). Retrieved March 23, 2014 from http://www.smeinfo.com.my/

SME Corporation Malaysia (Official Website). (2011). Retrieved February 26, 2014 from http://www.smecorp.gov.my/vn2/

Virdi, A. A. (2005). Risk Management among SMEs. Retrieved from http://www.cpaireland.ie/docs/defaultsource/business-resource/icaew---risk-management-among-smes.pdf?sfvrsn=2

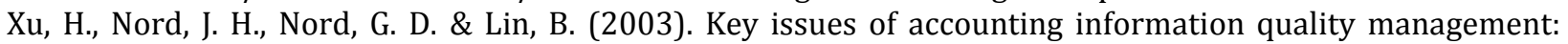
Australian case studies. Industrial Management and Data Systems, 103(7), 461-470. 